American Journal of Primatology 52:55-60 (2000)

\title{
Prehension in Infant Capuchins (Cebus apella) From Six Weeks to Twenty-Four Weeks: Video Analysis of Form and Symmetry
}

LEAH ADAMS-CURTIS ${ }^{1}$, DOROTHY FRAGASZY ${ }^{*}$, AND NANCY ENGLAND ${ }^{3}$

${ }^{1}$ Department of Psychology, Millikin University, Decatur, Illinois

${ }^{2}$ Department of Psychology, University of Georgia, Athens, Georgia

${ }^{3}$ R.R. \# 1, Maquon, Illinois

We analyzed the spontaneous prehensile activity of two infants living with their mothers in social groups, using videotapes taken once weekly from weeks 5 to 24. Prehensile activities were laterally symmetric. Unimanual activity predominated, although bimanual activity appeared at the same ages as unimanual activity. In most bimanual activity the two hands performed the same action, but complementary actions occurred from the onset of bimanual activity. Extrusion of the tongue towards objects out of reach was observed occasionally, as was precision grasping. Early prehension in capuchins is organized, as in human infants, in a matrix of exploratory activity integrated with vision and oral exploration. Capuchins present a useful model system for the study of manipulative development. Am. J. Primatol. 52:55-60, 2000.

(c) 2000 Wiley-Liss, Inc.

Key words: manipulation; bimanual activity; motor symmetry; tongue extrusion; precision grip; development

\section{INTRODUCTION}

This study provides normative information about manipulation in tufted capuchins (Cebus apella) during the first six months after birth. Capuchins, like humans, exhibit manipulative activity prior to the onset of independent locomotion [Fragaszy et al., 1991]. The similarity in the order of development across motor domains in capuchins and humans suggests there may be similarities in the pattern of neuromotor development. Information on the details of manipulation may be useful in assessing the significance of the gross similarity to human ontogeny present in capuchins.

We consider the appearance and use of bimanual actions and precision grips, and the possible existence of lateral asymmetry. These behaviors reflect the infant's ability to coordinate its digits and limbs, simultaneously and sequentially, and thus they reflect the integrated functioning of the sensorimotor apparatus in exploration. Neuromotor development and cognitive functioning are bound up with these behaviors [e.g., Thelen \& Smith, 1994; Michel \& Moore, 1995].

*Correspondence to: Dorothy Fragaszy, Department of Psychology, University of Georgia, Athens, Georgia 30602. E-mail: Doree@arches.uga.edu

Received 18 February 1998; accepted 26 June 2000 


\section{6 / Adams-Curtis et al. METHODS}

Two female infant tufted capuchins were videotaped for 30 min each at 7-day intervals from week 5 (days 29-35) through week 24 (days 121-128). We videotaped the two infants in their home enclosure with their mothers and other members of their social groups (one adult male, 5-6 adult females, and their offspring). The rooms contained perches, straw bedding, and a wide variety of hanging swings and smaller portable objects. Food and water were available ad libitum [see Fragaszy \& Adams-Curtis, 1991, for a complete description of housing]. The principal daily feeding occurred at about 8 A.M.; a second feeding occurred in midafternoon between 3:30 and 4 P.M.

We scheduled videotaping between 9 A.M. and 3 P.M. Videotaping was done from behind large windows at the front of the enclosure. Taping stopped if infants fell asleep and resumed when they awoke, so the sample reflects the time when the infants were (primarily) awake. Manipulative acts and other acts of interest, and the targets to which they were directed, were scored from the tapes during slow-motion playback using the vocabulary shown in Table 1. For scoring purposes, an act began with contact to an object, and ended when contact ended. The data set is composed of 2,620 acts.

For each act we recorded the hand (left or right) used to perform the action. For Pull and for Handle we recorded the form of grip (power or precision). In a power grip the object was supported so that movement of the object required movement of the wrist or arm. In a precision grip an object was supported so that movement could have been achieved by moving the fingers. We also differentiated unimanual and bimanual actions. Bimanual acts involved both hands acting at the same time during some portion of a single bout of contact. If the actions of the two hands had no temporal overlap, we scored them as separate unimanual acts.

Bimanual activity was further examined by breaking it into four categories in accord with whether the two hands performed 1) the same action directed

TABLE I. Definitions of Acts and Targets

\begin{tabular}{|c|c|}
\hline \multicolumn{2}{|l|}{ Hands } \\
\hline Touch & $\begin{array}{l}\text { Any non-grasping contact with a surface or object, including scraping, } \\
\text { patting, and rubbing }\end{array}$ \\
\hline Grasp & Fingers are closed around object; pulling object toward palm of hand \\
\hline Pull & A grip which brings an object to the animal, or animal to the object \\
\hline Hold & $\begin{array}{l}\text { A grip in which fingers are on two sides of an object and the object is not } \\
\text { supported on the palm }\end{array}$ \\
\hline Directed reach & $\begin{array}{l}\text { Arm extended in same direction as face. Act begins when arm first } \\
\text { begins extension, and ends when either arm or face begins } \\
\text { redirection. No contact of hand with object occurs. }\end{array}$ \\
\hline \multicolumn{2}{|l|}{ Mouth } \\
\hline Touch & Mouth touches object (includes licking, biting, and sniffing) \\
\hline Tongue extrusion & Tongue extended toward an object without making contact \\
\hline \multicolumn{2}{|l|}{ Targets } \\
\hline \multicolumn{2}{|l|}{ Self } \\
\hline \multicolumn{2}{|l|}{ Another animal } \\
\hline \multicolumn{2}{|l|}{ Perch or wall } \\
\hline \multicolumn{2}{|l|}{ Branch } \\
\hline \multicolumn{2}{|l|}{ Browse or straw } \\
\hline \multicolumn{2}{|l|}{ Food } \\
\hline Other & \\
\hline
\end{tabular}




\section{Development of Prehension in Capuchins / 57}

toward the same target (Isomorphic), 2) different actions directed toward the same target (Complementary), 3) the same action directed toward different targets (Redundant), or 4) different actions directed toward different targets (Differentiated). We also recorded tongue extrusion.

One person scored the tapes of the first infant through 23 weeks of age, and scored the tapes of the second infant through 8 weeks of age. A second person scored the remainder of the taped sessions. We calculated inter-observer reliability as percent agreement between the two scorers for the 30-min session of one infant at 17 weeks of age. Out of 140 acts total, agreement for frequency of use of the left and right hands was $80 \%$ and $94 \%$, respectively (mean $=88 \%$ ). Percent agreements for the frequency of occurrence of particular acts were: $81 \%$, Grasp; $100 \%$, Touch; and 75\%, involves mouth. All other acts were scored too infrequently ( $<3$ times for both observers) to calculate a meaningful measure of agreement.

For Subject 1, videotapes for all weeks were scored except 12, 21, and 22, which were inadvertently lost. From these data, we determined that manipulation did not change dramatically across weeks after week 14 . For Subject 2, even weeks past 15 were not scored. Thus, the values presented in this report are for the two subjects for weeks 5-11 and 13-15, 17, 19, and 23. One subject is represented in weeks $12,16,18,20$, and 24.

\section{RESULTS}

Manual activity appeared in week 6 for one infant, and for the other in week 7. The frequency of activity increased dramatically in weeks 9 and 10. Thereafter it varied about a mean of 154 acts per hour (see Fig. 1). Subject 1 exhibited almost all behaviors about a week earlier than Subject 2 .

Overall, unimanual actions occurred at a higher rate than bimanual actions (75 per hour, unimanual acts, vs. 46, bimanual acts). Fifty-two percent of unimanual acts consisted of grasping objects; $32 \%$ of touching. Holding, pulling, and directed reaching accounted for another $12 \%$ of unimanual manipulation. The average rate of unimanual touching increased from 3 times per hour in week 7 to 51 times per hour in week 10. Unimanual grasping reached a similar rate a week later. The rate of performing all other acts remained low $(<10$ times per hour) throughout the study.

We scored 465 (Subject 1) and 256 bimanual actions (Subject 2). Grasp was the first action to be performed bimanually. Both infants began grasping objects bimanually in the same week that they began grasping unimanually (week 6 in one subject; week 8 in the other). Other bimanual actions were either preceded in appearance by the unimanual counterpart action, or appeared in the same week as the unimanual action. The rate of both unimanual and bimanual activity rapidly increased at first, and then stabilized (see Fig. 1).

The largest proportion (70-74\%) of bimanual activity involved Isomorphic actions. Complementary actions constituted approximately 10-18\%, Redundant actions $7-13 \%$, and Differentiated actions $4-5 \%$ of bimanual activity. The distribution of bimanual activity across these four categories remained relatively stable across weeks. Complementary actions first appeared in weeks 8 and 9. The most common Complementary pattern was for one hand to hold or grasp an object or substrate, and the other hand to touch it. We further examined the role of the two hands in Complementary actions by categorizing Pull, Grasp, and Hold as support when paired with Touch in complementary activity and Hold as support when Pull was the active element. Support and manipulation of objects in Complementary activity were evenly distributed across hands (Left hand support, Sub- 
58 / Adams-Curtis et al.

\section{Rates per Hour of Manual Activity}
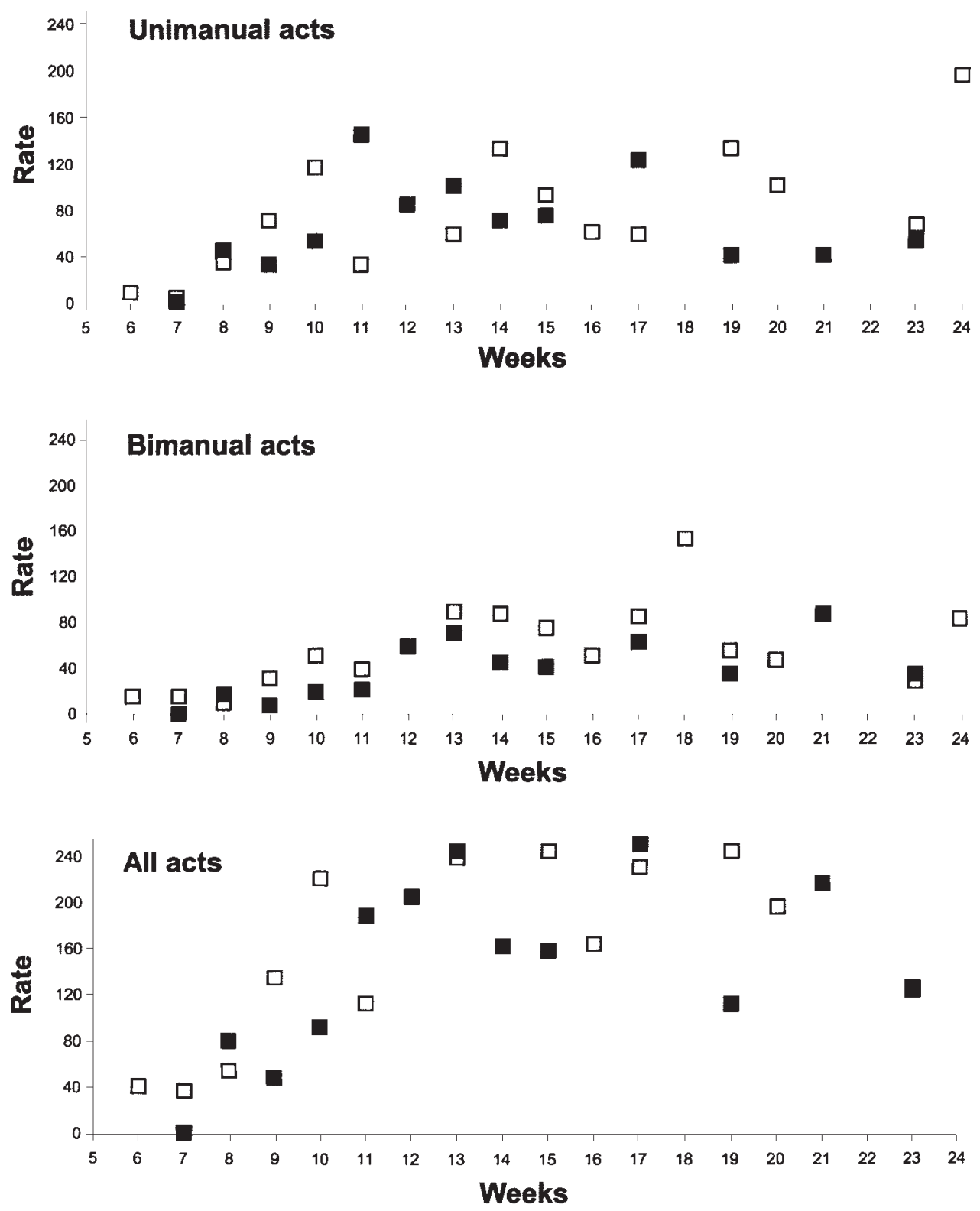

Fig. 1. Rate per hour of prehensile acts per week for each subject. Subject 1 is depicted by open squares, and Subject 2 by solid squares. Subject 1 performed all acts at a rate of 594 acts per hour, which is off the scale of the graph, in week 18.

ject $1=23$ and Subject $2=24$ occurrences; Left hand manipulation, Subject $1=$ 26 and Subject $2=20$ with three ambiguous cases) and across weeks. There is no evidence in our data of an emerging preference for one hand to take the active role in manipulation. 


\section{Development of Prehension in Capuchins / 59}

A precision grip was first recorded in week 8, but was used infrequently by both infants, and no change was evident in its frequency. The weekly proportional contribution of manipulation which incorporated the precision grip ranged from $0-35 \%$ per infant.

We found no evidence of lateral asymmetry in unimanual actions. Use of the two hands appeared to be randomly distributed across weeks. For Subject 1, use of the left hand ranged from $100 \%$ (week 8) to $25 \%$ (week 11). After week 9, use of the left hand varied between $25-75 \%$ of unimanual activity. For Subject 2, use of the left hand ranged from $0 \%$ (week 6) to $100 \%$ (week 7). After week 7, use of the left hand was within $25-75 \%$ of all unimanual activity. Given that manual activity was infrequent up to week 8 , a difference of one to three actions for one hand or the other could produce a large difference in percentage use of each hand during these early weeks.

One infant first used her mouth in exploration (to touch a surface) in week 6 , and the second infant in week 8 . Both infants performed over $80 \%$ of exploration with the mouth in conjunction with activity by one or both hands. Subject 1 occasionally used the mouth alone through 24 weeks, and Subject 2 through week 14. Extending the tongue toward an object occurred occasionally (eight times between weeks 8 and 13 in one subject; three times between weeks 10 and 19 in the other). The hands or mouth generally contacted an object within a few seconds following extension of the tongue. The infants never used the tail or feet to prehend objects.

The two infants first touched other animals or nearby surfaces (e.g., the perch) with their hands. Actions directed toward their own bodies appeared during week 8 in both infants. Manipulation of other animals peaked in weeks 8 through 10 for both infants. The infants first contacted smaller portable objects (straw, browse, food) in weeks 11 and 13, activities that were enabled by the infants beginning to move off a carrier and to encounter objects on their own. The self and food were the least frequent targets of manipulation, accounting for $2 \%$ and $12 \%$ of activity for the two infants. Most activity with food occurred after week 17. All classes of targets elicited uniform proportions of unimanual and bimanual activity, and uniform proportions of unimanual actions with the left and right hands.

\section{DISCUSSION}

This study replicates the findings of previous studies of manipulative development in tufted capuchins [Fragaszy, 1989; Adams-Curtis \& Fragaszy, 1994; Byrne \& Suomi, 1995]. In addition, this study showed that bimanual actions appeared close in time to the unimanual version of the same actions. Complementary actions were observed as soon as manipulation began to be frequent ( 8 and 9 weeks). Infants did not develop stable preferences for the use of one hand over the other.

We also showed that the consistency of manual activity documented previously using real-time data collection methods [Adams-Curtis \& Fragaszy, 1994; Byrne \& Suomi, 1995] extends to the organization of activity by the two hands, singly or together, and the involvement of other body parts (mouth, feet, tail). The findings suggest that neuromotor development is not the limiting factor in manipulative development of the older infant (16 weeks and on). The onset of selffeeding in the fifth month or later in captivity and in nature therefore does not reflect an inability to manage the manual aspects of feeding earlier in life. Other characteristics (such as dentition or body size) probably have greater influence on feeding activity than do manual capabilities [Fragaszy \& Adams-Curtis, 1997]. 


\section{0 / Adams-Curtis et al.}

These data are not sufficient to draw detailed comparisons with human infants, for whom we have a rich data base on spontaneous manipulation under a variety of conditions [see Michel \& Moore, 1995; Bushnell \& Boudreau, 1993; von Hofsten, 1990, for review]. However, we can say that tufted capuchin monkeys from birth through about 16 weeks of age, at which time manipulation is very frequent and well-controlled, could provide a particularly useful developmental model of skilled manual activity for several reasons. First, they use their hands almost exclusively in exploration and manipulation (vs. the feet or mouth) [see also Natale, 1989]. Other species of monkeys for which data are available display less frequent spontaneous manipulation and greater frequency of buccal prehension and mouthing [e.g., macaques; Poti, 1989], or less dexterous activity [e.g., squirrel monkeys; Fragaszy, 1983]. Second, capuchins exhibit frequent bimanual activity. It is unknown if the rate of bimanual activity observed in these monkeys is typical of other species as well. As bimanual activity is most often associated with visual regard and continued handling of an object, it is not likely to be prominent in those individuals that rely primarily on mouthing to explore objects.

\section{ACKNOWLEDGMENTS}

The data reported here were collected while the authors were at Washington State University. The research was supported by PHS Grant MH-41543 to D. Fragaszy, and preparation of the manuscript was supported by a Career Development Award K-02 MH00694 to D. Fragaszy and PHS Grant HD06016 to Georgia State University. We thank Carrie Rosengart for assistance in creating the figure.

\section{REFERENCES}

Adams-Curtis L, Fragaszy DM. 1994. Development of manipulation in capuchin monkeys during the first six months. Dev Psychobiol 27:123-136.

Bushnell E, Boudreau, JP. 1993. Motor development and the mind: the potential role of motor abilities as a determinant of aspects of perceptual development. Child Dev 64:1005-1021.

Byrne G, Suomi S. 1995. Development of activity patterns, social interactions, and exploratory behavior in infant tufted capuchins (Cebus apella). Am J Primatol 35:255-270.

Fragaszy DM. 1983. Preliminary quantitative studies of prehension in squirrel monkeys (Saimiri sciureus). Brain Behav Evol 23:81-92.

Fragaszy DM. 1989. States and activity in an infant capuchin from birth to eleven weeks. Dev Psychobiol 11: 141-157.

Fragaszy DM, Adams-Curtis L. 1991. Generative aspects of manipulation in tufted capuchin monkeys (Cebus apella). J Comp Psych 105:387-397.

Fragaszy DM, Baer J, Adams-Curtis L. 1991. Behavioral development in squirrel monkeys (Saimiri sciureus) and tufted capuchins (Cebus apella) from birth through 6 months. Dev Psychobiol 24:375-393.
Fragaszy DM, Adams-Curtis L. 1997. Developmental changes in manipulation in tufted capuchins (Cebus apella) from birth through two years, and their relation to foraging and weaning. J Comp Psych 111:201-211.

Michel G, Moore C. 1995. Developmental psychobiology. Cambridge: MIT Press. 516 p.

Natale F. 1989. Patterns of object manipulation. In: Antinucci F, editor. Cognitive structure and development in nonhuman primates. Hillsdale, New Jersey: Lawrence Erlbaum. p 145-161.

Poti P. 1989. Early sensorimotor development in macaques. In: Antinucci F, editor. Cognitive structure and development in nonhuman primates. Hillsdale, New Jersey: Lawrence Erlbaum. p 39-53.

Thelen E, Smith LA. 1994. Dynamic systems approach to the development of cognition and action. Cambridge, Massachusetts: MIT Press. 376 p.

von Hofsten CA. 1990. A perception-action perspective on the development of manual movements. In: Jeannerod M, editor. Attention and performance, vol 13. Motor representation and control. Hillsdale, New Jersey: Lawrence Erlbaum. p 739-762. 